\title{
INTERNET: Investigating New Technology's Evolving Role, Nature and Effects on Transport
}

\author{
Glenn Lyons* \\ Transportation Research Group, University of Southampton, Southampton SO17 1BJ
}

\begin{abstract}
In the space of only a few years the Internet has emerged as a mainstream communications medium providing a growing proportion of the population with virtual access to goods, people, opportunities and services. Against a backdrop of highlighting how teleshopping and teleworking alongside traveller information services are advancing as a consequence of the Internet, this paper suggests that the Internet and the virtual mobility it affords must in due course be explicitly addressed within an integrated transport policy. The paper explores the relationships between use of information and communications technology and personal travel highlighting the importance of social issues in gauging whether or not a net positive effect in terms of travel demand and tripmaking can arise from increasing use of the Internet. Suggestions for a policy approach are also made.
\end{abstract}

Keywords: Internet; Travel demand; Teleservices; Teleshopping; Teleworking

\section{Introduction}

At the turn of the millennium the Internet is a legacy from the end of one century that holds the prospect of becoming a significant part of our lives in the next. To understand why this prospect exists it is necessary to consider the role information plays in the way we live and the way in which society functions. Most of our daily lives are concerned with 
information management, exchange and interpretation. Many of the activities that we partake in are primarily to obtain, access and/or exchange information. In turn, the reason we travel is in order to participate in activities. Therefore, to a degree, travel demand and flows of vehicular traffic and people are derived from the need or desire to exchange information.

This paper looks closely at the Internet in terms of how it is rapidly becoming, for a growing proportion of the population, a part of our everyday lives. In its ten year spending plan for transport (DETR, 2000a) to support its integrated transport policy (DETR 1998), the UK government states that "social and technological changes will also alter patterns of behaviour in unforeseen ways". As the Internet becomes an integral part of our lifestyles so too will it influence the nature of personal travel. Yet in terms of transport policy it appears that this is not currently being confronted. The interactions between the Internet, society and transport are complex with the Internet's effects set to become increasingly significant as this paper seeks to highlight. There is an urgent need for transport researchers to improve our understanding of this evolving situation as in turn there is a need for transport planners and policymakers to begin taking greater account of and responding to the potential impacts of and role of the Internet within an integrated transport policy.

The paper first provides statistics reflecting to what extent the Internet is becoming a part of our lives and highlights the establishment of longitudinal surveys to monitor this over time. Examples of some key current uses of the Internet that are impacting upon travel demand and tripmaking are then considered. Subsequently the relationships between transport, the Internet and society are discussed in more detail drawing on views from commentators from both within and beyond mainstream transport studies. The paper concludes by returning to a consideration of how transport policy, planning and research is or should be addressing the role and impact of the Internet. There are a number of other papers

\footnotetext{
* Corresponding author. Tel: +44-23-8059-4657; fax: +44-23-8059-3152. E-mail address: g.lyons@soton.ac.uk
} 
that address the relationships between transport and telecommunications and these are cited later. However, this paper specifically presents a UK perspective whereas much previous research has originated in the US. It focuses particularly on the Internet and personal travel rather than the broader fields of telecommunications and transport (though this is not to imply that the uses and impacts of the Internet do not extend into other aspects of transport).

\section{Internet access}

The Internet is at the heart of a technological revolution that presents society with the opportunity to manage, exchange and interpret information electronically. It represents an unprecedented opportunity for multimedia, global information exchange. In itself the Internet is the physical infrastructure over which information can move. It provides an increasingly dense electronic connectivity between people in our society. The capacity of that infrastructure to allow movement of information is important with a clear analogy between bandwidth and roadwidth. However, it is how that connectivity and capacity is used that is of greater interest - i.e. the ways in which information can be represented and accessed. The two principal forms of information exchange over the Internet are electronic mail (email) and the world wide web (web). The web was only invented in 1993 and yet web pages worldwide already number billions. The number of emails worldwide sent daily is now many billions. Just as physical mobility is undertaken to access people, goods, services and opportunities, so too is 'virtual mobility' using the Internet a means, increasingly, to achieve access.

Figure 1 shows the worldwide number of Internet hosts (computers connected to the Internet) over time - it is a measure of the minimum size of the Internet. In the six year period from 1995 to 2001 the Internet's size has increased by over 1700 per cent. As of August 2001 one source (NUA, 2001) puts the number of Internet users in Europe at 155 million with Canada and the USA having 181 million. 


\section{Figure 1}

One of the problems with trying to identify statistics assessing access to and use of the Internet, particularly with regard to determining trends over time, is that a vast array of different survey results and estimates are available from different sources making reliability and comparison difficult to judge. Fortunately more recently, national statistics institutes have begun to encompass Internet access and use within their surveys. The US Census Bureau includes computer use as a supplement to its Current Population Survey and since 1997 has also included questions on Internet use. In August 2000, 51 per cent (54 million) of US households had at least one personal computer or laptop and 41.5 per cent of households had at least one member of the household using the Internet at home (compared to only 18 per cent in 1997) (US Census Bureau, 2001). In the UK, the Office for National Statistics is placing questions about the Internet and e-commerce in four surveys of households and individuals: the National Statistics 'Omnibus' Survey; the Family Expenditure Survey; the General Household Survey; and the Time Use Survey. Results are published in a quarterly release 'Internet Access' (Rowlatt, 2001). For the second quarter of 2001 it was estimated that 9.4 million UK households had access to the Internet (up from 2.2 million for the same quarter in 1998) - 35 per cent of households had access from home computers with 38 per cent having access using all forms of access (survey figures from April 2000 onwards cover access via new technologies such as digital TV) (Office for National Statistics, 2001a). 51 per cent of adults have accessed the Internet at some time. The US and UK access trends are shown in Figure 2.

\section{Figure 2}

Anecdotally, different views are expressed about the extent to which the elderly make use of the Internet. Official UK statistics show that whilst 'silver surfers' may be appreciable in their numbers, Internet use decreases with age (see Figure 3). Similarly in the US, Internet 
access at home is much lower amongst those aged 55 years and above compared to the overall adult population.

\section{Figure 3}

Internet access can also be considered according to gender and socioeconomic status. As of July 2001, 56 per cent of adult males in the UK had used the Internet (up from 52 per cent in July 2000) compared to 47 per cent of adult females (up from 39 per cent in July 2000) (Office for National Statistics, 2001a). Levels of access correlate closely with gross household income with 71 per cent of households in the highest decile income group having home access to the Internet compared to 7 per cent in the lowest decile group (Office for National Statistics, 2001b). As at January 2001, 78 per cent of adults in households headed by a professional had used the Internet compared to 37 per cent and 27 per cent of adults in households headed by a skilled manual and unskilled individual respectively (Office for National Statistics, 2001c). Figure 4 highlights the degree of use of new technologies across the different social classes. Internet access from class $A B$ across to class DE declines although the market penetration of digital TV is more even across social classes. Digital television services can enable Internet access. Internet enabled set-top boxes are also being produced to allow Internet access through ordinary television sets. Internet-enabled games consoles such as the Sega Dreamcast launched in late 1999 also show the scope for growth in alternatives to PC access to the Internet (UK Online, 2000). Such alternative forms of home access hold the prospect of facilitating strong Internet access penetration over time across all social classes. Many households may be unable to afford or justify the purchase of a PC to access the Internet whereas TV sets and games consoles may be more popular items bought because of their primary purposes while also providing Internet access.

\section{Figure 4}




\section{Uses of the Internet}

Some of the ways in which the Internet is being used by those within this growing proportion of the population in their everyday lives are now considered. Table 1 indicates broadly the extent to which we undertake different activities outside the home in Great Britain. The most frequently undertaken activity in terms of travel is shopping. It accounts for 21 per cent of all journeys and 58 per cent of those journeys are undertaken by car. Second to this comes commuting accounting for 16 per cent of all journeys, 70 per cent of which are undertaken by car. The focus in this section is therefore on how the Internet can offer an alternative for journeys made for these purposes (though it is not implied that the Internet is not used for other purposes identified in the Table). For all journeys that are made there is a role for information to assist the traveller. The Internet is proving instrumental in this regard and is therefore also discussed.

\section{Table 1}

The intention of this part of the paper is to highlight how concepts and notions that, in some cases, have been around for many years are now fast becoming mainstream features of society and features that are technologically sophisticated in ways that overshadow their preceding incarnations. Hepworth and Ducatel (1992) provide a reminder that the trade-off between telecommunications and transport is not new and indeed they also specifically considered the merits of teleworking and teleshopping. What is noteworthy (as mentioned below) is how their observations compare to what we see today ten years on.

\subsection{Shopping}

Shopping is an activity that is predominantly concerned with information exchange goods are viewed, selected, purchased and taken home. (This is something of an oversimplification with regard to goods being viewed - in practice this extends to cover goods 
being touched, smelled, tried on etc.). These four stages of the activity can be completed without needing to visit a high street retail outlet. Indeed catalogue shopping for clothing and household goods has existed for many years and continues to do so in the face of the Internet and websites that seek to offer a similar service. However, the form of shopping that is most frequently undertaken is grocery shopping. In the UK towards the end of the $20^{\text {th }}$ century there was a proliferation of development of out-of-town supermarkets. As a result both the location of supermarkets and the need to transport goods home has meant that a substantial number of grocery shopping trips are undertaken by car. The huge and continually changing range of products that a typical supermarket provides, coupled with continually changing prices renders the catalogue and phone operation used for clothes shopping inappropriate.

In 1992, Hepworth and Ducatel observed that "teleshopping in Britain is still at an experimental stage ... the number of households equipped with the technology for teleshopping - a computer terminal - is a minute proportion of the shopping population” and suggested that "there is no natural way for grocery teleshopping to evolve alongside superstore retailing”. They reinforced a pessimistic outlook for grocery teleshopping by noting that "the preoccupation of senior management is with property development and acquisition, which is again not a major issue in teleshopping”. These statements at that time were appropriate yet with the benefit of hindsight they did not foresee the Government's introduction of Planning Policy Guidance Note 13 (DOE/DOT, 1994) which seeks to kerb out-of-town retail property development. Neither did they foresee the rapid increase in the availability, affordability and capability of computing technology and the invention of the web.

Grocery shopping over the Internet is now a reality in the UK with all the major supermarkets offering such a service. Their styles of operation all vary but a brief description of Tesco.com aptly provides an illustration of what is being achieved. The following detailed 
description of the service may seem out of place. However, it is intentionally included to convey how the capabilities of the Internet technology are being exploited to try and deliver a sophisticated but user-friendly virtual service that can compete with its real counterpart. Such a service exhibits features that were only speculated about as recently as a few years ago (Cairns, 1996).

Tesco’s online supermarket operation offers access to (almost) all the products sold in its conventional stores, including frozen food and fresh produce, with the same prices and special offers. Having signed in, the user can search for products either by keyword or category. The company has had a loyalty card scheme for many years. Whilst this provides 'rewards' for the shopper's custom it also allows the company to monitor an individual's shopping activities and product preferences. This means the online supermarket can provide details of a shopper's 'favourites' - items that have been purchased previously. Since many repeat purchases are made with grocery shopping this allows the online shopping process to be much quicker. As the shopper moves round the 'store' items are selected and added to the shopping basket. Once the shopping is complete it is then necessary to identify a time and date slot for delivery of the shopping to the user's home. Two-hour delivery slots are available between 10am and 10pm Monday to Saturday, and between 10am and 3pm on Sunday. The final list of specific goods required is then relayed to the local branch of the supermarket where the goods are gathered by a 'personal shopper' (a human being!). The online store allows the user to attach notes next to individual items to be purchased (for example indicating that green rather than ripe bananas are preferred). The shopping is then delivered to the user’s home. Initially the flat rate delivery charge was $£ 5$.

This particular shopping service covers 90 per cent of the population. With a base of one million users who make 70,000 online orders per week (CNN, 2001) its sales for 1999 totalled $£ 125 \mathrm{~m}$ representing 0.6 per cent of total retail sales for the company (Retail Logistics 
Task Force, 2001). Whilst at present remote grocery shopping sales represent only a small fraction of one per cent of total sales, the Institute of Grocery Distribution (http://www.igd.com) cites a number of reasons why it expects remote shopping demand to rise:

- an increase in personal disposable income with greater capacity to pay for home delivery;

- growing affluence of retirees - the group who find shopping most physically tiring;

- an increase in length of the average working week leaving less time for shopping;

- increasing numbers of people in work - particularly women;

- a growing number of leisure options making it worthwhile to save time shopping; and

- a proliferation of home delivery services for other products (books, pizzas, CDs etc.) which help accustom people to the benefits.

Indeed online grocery sales in the UK are forecast to increase dramatically from $£ 530 \mathrm{~m}$ in 2000 to $£ 4.96 \mathrm{bn}$ in 2005 equating to 6.6 million and 62.5 million separate deliveries respectively. The logistical requirement of extending the end of the supply chain to people's front doors is problematic and potentially extremely expensive, not least because of the paradox that "as customer demand for home shopping increases, the likelihood of their being at home to receive their purchases decreases” (Retail Logistics Task Force, 2001). There is also the problem of parking to unload delivery vehicles in residential areas at times of day when people are at home to receive their goods. The costs of delivering an online grocery shopping service (involving order processing, storage, picking, packing and transport) currently are not fully met by the charges levied as supermarkets seek to develop market share. Consequently there are calls for research to evaluate the likely growth in demand for home shopping and to examine the options for effective delivery and collection point concepts (ibid, 2001). 
There are varying speculative views about future uptake of teleshopping and its consequences for personal travel and indeed goods movement. One UK source (Dodgson, 2000) estimates a reduction in car shopping travel due to e-commerce of 10 per cent by 2010 with only a slight increase (0.5 per cent) in travel by delivery vans. Meanwhile Transport en Logistiek Nederland (http://www.tln.nl/) estimates that e-commerce will take a 10 per cent share of the food products market by 2005 but that this will lead to the use of smaller vans instead of larger distribution vehicles for deliveries with an 8 per cent increase in road journeys relating to business-to-customer e-commerce.

\subsection{Teleworking}

Teleworking is not a new phenomenon and there is a substantial base of literature concerning this working practice including its (potential) consequences for transport (see for example: Mokhtarian, 1991; Nilles, 1991; Lund and Mokhtarian, 1994; Niles, 1994; Handy and Mokhtarian, 1996; and Lyons, 1998). Decades ago there was considerable optimism that the numbers of people teleworking would increase dramatically once availability of computers in the home increased substantially. In the intervening years no dramatic increase has been apparent. 10 years ago it was estimated that teleworkers in Britain numbered between 3000 and 10000 (Hepworth and Ducatel, 1992) (it seemed implicit from these authors' commentary that reference was to teleworking as a full-time working practice). As Salomon (1998) notes, "methodologically, forecasts of telecommuting tend to emphasize technological change while underestimating the social implications which determine the adoption of such technologies". For example, difficulty (or perceived difficulty) of managing personnel at a distance and isolation are illustrative of reasons that have inhibited widespread take-up. Take-up is also influenced by employer support and the degree of understanding of the working practice itself. It a recent comprehensive review of take-up and transport issues 
surrounding teleworking, Illegems et al (2001) point to the need for teleworking to be an integral part of an organisation's strategy in order to flourish. They also note that "Individuals often describe their job as ill-suited for teleworking because a part of its requires their physical presence at the headquarters. In fact they should adopt the opposite view. Most of the current jobs have one or more tasks that could easily be performed through teleworking. Teleworking is however often wrongly considered as a full-time option.”

One of the problems in terms of assessing teleworking and its impacts is that it is not a working practice that has a singular definition and until recently (unambiguous) questions were not included in surveys conducted by national statistics institutes. In the UK this has changed. Since 1997 specific questions have been included in the Spring Labour Force Survey (LFS). The LFS defines as teleworkers, people who do some paid or unpaid work in their own home and who could not do so without using both a telephone and a computer. Table 2 shows the extent of teleworking in the UK with over 6 per cent of the workforce now practicing it. This perhaps suggests that the long anticipated widespread uptake of teleworking may finally be occurring. Of course not all forms of employment are suitable for teleworking (notwithstanding the point by Illegems et al as mentioned above) and so teleworking may not have the same size of potential market as teleshopping. Nevertheless, the makeup of the employment market is changing. Between 1991 and 2001 the number of UK employee jobs in the service industries (argued to be more suited to teleworking), as a share of employee jobs across all industries and services, increased from 73 to 78 per cent (Office for National Statistics, 2001d).

\section{Table 2}

Working from home does not necessarily require the availability of Internet access or of any technology. However, in modern office environments computers and transfer of information between them has become an integral part of everyday work. Email is used 
increasingly to communicate in the workplace. As such, it may now often be considered a prerequisite of working from home that access to the Internet is available. Technology has not (yet) delivered the paperless office (world paper consumption is projected to nearly doubled from some 225 million tonnes in 1990 to 425 million tonnes in 2010 (Robins and Roberts, 1996)). Nevertheless, the Internet allows transfer of electronic documents either directly or as attachments to email messages. As such, homeworkers can readily receive, work on and dispatch correspondence, reports etc. Table 2 shows that the most rapidly growing form of teleworking in the UK is occasional teleworking. This in particular is the form of teleworking that substitutes working at home on some days for the more regular practice of commuting to/from the normal workplace. It would seem that the falling costs of computing and Internet access (an Internet-ready PC can now be purchased for under £500) make it relatively inexpensive to now have an acceptable office set-up at home for occasional use. Further, the increasing use of laptop computers which, when connected to a mobile phone, can access the Internet to allow email and document transfer is facilitating a culture of mobile working environments. Computers and the Internet allow (for some sectors of the workforce) working in the office, on the train, in the hotel and at home. In effect the Internet is diminishing the importance of spatial location for working. This seems to be proving a welcome development for many in society who are striving to manage increasingly complex and demanding lifestyles.

\subsection{Traveller information}

Discussion of teleshopping and teleworking above is illustrative of how the Internet can play a part in enabling individuals to undertake tasks and participate in activities without recourse to make trips outside of the home. These are among the most commonly cited examples of teleservices though there are others available via the Internet such as online 
banking, online estate agents and house hunting and online medical consultation. However, the Internet is also playing an increasingly important part in the provision of travel information to assist individuals in making travel choices, planning their journeys and booking and paying for travel tickets. The UK government's vision for the future of traveller information highlights this:

"Transport Direct was announced in July 2000 as part of the government's ten year spending plan for transport. It is an ambitious Programme to provide the U.K. with a travel information service that can present the public with the opportunity to compare travel options across public and private transport modes. Using the Internet as its principal delivery medium it seeks to offer a one-stopshop journey planning, booking and payment service, complemented with realtime update information." (Lyons et al, 2001).

A journey by public transport can involve using more than one mode and/or more than one service. If the public are to be encouraged to consider travelling by alternatives to the car then it must be straightforward and convenient for them to do so. This not only concerns the journey itself but the process of making plans for that journey (or indeed even being aware of the travel options available). Most commonly, journey planning will require access to timetable information and possibly fares information. Particularly in the UK where operation of the public transport industry (bus, coach and rail) is mainly in the hands of a considerable number of different private sector companies, such information resides in multiple locations both in electronic databases and on paper. If the public are faced with the task of piecing together the information they need, such inconvenience may well inhibit them considering alternatives to the car. To some extent this inconvenience has been limited by the availability of paper-based timetable information and telephone information services. 
However, call-centre operatives must also be supported by suitable mechanisms for accessing information required by callers.

The Internet with its information exchange capabilities is proving highly compatible with the needs associated with managing, interpreting and exchanging traveller information. There are now over 400 web sites in the UK providing public transport information (Austin, 1999). Journey planners are increasingly common and heavily used. A journey planner allows the user to enter details of an intended journey and the web service then returns a page setting out corresponding travel options and itineraries. At present in the UK such journey planners are limited to a particular mode or region. However the Internet allows a back-office connectivity of different journey planners' databases. Current research and development is looking to exploit this. The aim is that instead of an individual needing to visit a number of website journey planners to plan a journey that involves more than one mode or region, a single enquiry can be made. The back-office operations will assemble the information from multiple database sources and relay it back to the individual (Fingerle et al, 1998). A number of similar developments of systems and communications protocols are moving forward founded essentially on the communication (enabled by the Internet) between distributed heterogeneous databases.

There are a number of websites that provide the facility not only to plan a journey by collective transport but to also book and pay for the travel ticket. In the case of the airlines and coach industry in the UK, the individual may even be given a 'virtual ticket' (a unique ID number) that can be presented for travel. There are now several providers of online planning, booking and payment services for rail travel in the UK. For each of these, however, the end of the process still involves the physical delivery of the tickets to the person's home or the collection of the tickets. 
The ultimate aim in the UK is for an integrated information service where the enquirer can stipulate an origin and destination and the service will return comparable information for both the journey by car and for alternatives to travel solely by car. By providing such a 'onestop-shop' facility on the Internet there is the prospect of challenging people's perceptions of different travel options and ensuring better informed travel decisions are made. The hope is that for some people, some of the time, in some situations, this will result in a change of mode choice and a decision not to travel by car.

The Internet's connectivity is not only of vital importance to the back-office operation of such services. It also makes the information widely accessible to a growing proportion of the population with, arguably, greater prospect for influencing patterns of travel and particularly mode share at the aggregate level than previous forms of information provision and dissemination media. It has been suggested (Slevin, 1997) that it might be particularly effective at targeting those seen to be least exposed to (information on) modes of travel other than the car - the stereotypical affluent car owning office worker who has an Internet accessible computer on his desk. The public's use of the Internet to access traveller information appears to be growing. In the UK in 1997 Railtrack launched its Internet rail journey planner. With very little advertising expenditure and in spite of only providing timetable-based information (the year previously a national timetable and fares telephone information service had been launched by the Association of Train Operating Companies) the service was processing in excess of one million journey enquiries a week by 1999 - a figure comparable, at that time, to the number of calls to the national telephone service (The Institute of Logistics and Transport, 1999). 


\section{The Internet, transport and society}

Set against this backdrop of what the Internet is making possible in terms of information exchange and teleservices, the paper now turns to consider in more detail whether and in what ways society reacts to such possibilities and notably what the current and future consequences might be for transport and patterns of travel.

\subsection{The hope of substitution}

From the perspective of the transport planner and policymaker, the uppermost desired consequence of Internet access must be that virtual mobility directly substitutes for physical travel thereby reducing the absolute level of tripmaking.

There are two principal factors at play in influencing people's choice between 'real space activities' and their substitution with 'virtual space activities' - the generalised cost of reaching amenities and services and the quality or attractiveness of those amenities and services. The term accessibility (a function of the two factors) can then be used to represent the net appeal to an individual. Generalised cost refers to "a measure combining all the main attributes related to the disutility of a journey” (Ortúzar and Willumsen, 1998 p153). It includes travel time and monetary cost as well as safety, comfort, convenience etc.

A virtual trip on the Internet is almost instantaneous (although people's tolerance of waiting a few seconds or minutes to access websites can seem disproportionately low compared to that of the minutes or hours that can be spent waiting in traffic jams). The monetary cost tends not to be concerned with getting to the 'destination' but with participating in information exchange at the destination or website for example. (In fact when one refers to visiting a website what actually happens is that the pages from that site are sent to the individual - i.e. the activity comes to the individual rather than the individual going to the activity.) The monetary cost when it exists for the individual can either be in the form of a 
fixed cost such as a monthly subscription for Internet access or a variable cost where metered access charges the user for the time spent on the Internet.

A brief aside is warranted concerning fixed and variable costs. An individual can attain physical mobility either through payment of both fixed and variable cost or only variable costs. Ownership and use of a car constitutes the former while use of a bus, taxi or train can be an example of the latter. Similarly, to attain virtual mobility an individual can own and use an Internet-ready computer or alternatively an individual could use a public access point (an Internet kiosk or Internet café) where only a variable cost is incurred.

In terms of generalised cost, as discussed above, virtual accessibility is likely to win hands down. The question therefore becomes one of to what extent the attractiveness of activities accessed virtually compares favourably with that of equivalent activities accessed physically and to what extent lower generalised cost of virtual access can be traded off against probable relative deficiencies of virtual activity attractiveness. Efforts continue to improve attractiveness of virtual activities. The Tesco.com business for example has gone to great lengths to provide a virtual service (within its limitations) that is reflective as much as possible of consumer needs and which offers a convenient and satisfactory shopping experience. However, as highlighted later in Table 3, whilst virtual substitutes may be effective in meeting the functional requirements of activities (e.g. 'I go shopping to replenish the household food stock') they may well fall short of meeting other social or psychological requirements (e.g. 'Going shopping is a chance to get out of the house and see and meet people'). If virtual access is inadequate in such regards then it is possible that either substitution will not take place or that alongside substitution other physical travel and activities will be engaged in to satisfy social and psychological needs. 


\subsection{Additional considerations to substitution}

Even before the advent of the web and widespread use of the Internet, the potential relationships between telecommunications and transport were being discussed. Mokhtarian (1990), drawing on the earlier work of Salomon (1986), highlighted four different kinds of relationships:

i. $\quad$ substitution (e.g., telecommunications decreases travel);

ii. $\quad$ enhancement (e.g., telecommunications directly stimulates travel);

iii. operational efficiency (e.g., telecommunications improves travel by making the transportation system more efficient); and

iv. indirect, long-term impacts (e.g., telecommunications may ultimately affect land use, which will affect travel).

Elsewhere, Mokhtarian (1997) notes that "the idea that telecommunications technology could substitute for travel dawned on people soon after the invention of the telephone". However, she goes on in this paper to note "Historically, transportation and communications have been complements to each other, both increasing concurrently, rather than substitutes for each other. And we have no reason to expect that relationship to change.” This view is echoed in other commentaries. Adams (2000) suggests that electronic mobility and physical travel are highly correlated over space and time and states that "The hope that extensive use of telecommunications will obviate the need for travel and the movement of goods, rests upon a decoupling of the trends of electronic and physical mobility for which there is no precedent.” Urry (1999) also questions whether 'corporeal travel' can be reduced through the development of virtual mobility. Others express a frustration that sufficient attention is not paid to past experiences of non-corporeal mobility in contemplating the consequences of emerging ICTs - "There is remarkably little work on the genealogy of ICT 
practices, and this does not help matters since it allows so many commentators to claim that ICT is 'new'”' (Thrift, 1999).

Recent empirical analyses in Norway involved two survey datasets, obtained from the same set of respondents, concerning travel activities and the use of ICT at home (Hjorthol, 2002). This work concluded that "The analyses give some indications of adjusting work and family life, but the net effect gives no reduction in travel activity. Stationary communication [ICT use] seems to be a supplement to activities based on mobile technology [physical travel], but it gives people more spatial and temporal options.” These comments highlight a subtle but important point of clarification in judging the consequences of Internet use for transport. Whilst the net effect of virtual mobility on the amount of travel might be zero this does not equate to there being no effect. Both substitution and enhancement may simultaneously be at work causing changes to activity patterns and a redistribution of tripmaking in time and space which may be important for transport policy to take account of.

As many researchers have suggested or observed, the saving in travel time accrued by substitution may be reinvested in other travel. Some transport analysts subscribe to the view that there is a travel time budget, i.e. "people spend somewhat more than one hour per day travelling, on average, despite widely differing transportation infrastructures, geographies, cultures and per capita income levels” (Schafer, 1998). Thereby where people have acquired access to modes of travel that are faster (e.g. the Internet) so, in turn, rather than saving time on travel, they begin to make more trips or travel over longer distances.

Travel information can potentially improve operational efficiency of transport by helping to bring about a more sustainable distribution of travel demand across modes. However, if traveller information is of benefit to the individual then it may be so because it has helped in identifying a cheaper, quicker, less stressful, more reliable means of making a journey. In other words it has helped reduce the generalised cost of travel. Whilst a higher 
generalised cost would be likely to discourage the amount of travel, so in turn, a reduced generalised cost may be inclined to encourage more travel over time.

\subsection{Considering future consequences of the Internet}

The four relationships set out earlier principally concern telecommunications and transport. Exploratory work by Kenyon et al (2002) is looking at a triangle of influence between social participation, the Internet and transport. Social exclusion is high on the political agenda in the UK and investment is going into a number of deprived areas to establish them as ‘wired-up’ communities. Much as Mokhtarian (1996) acknowledges that “telecommunications has an enormous potential to change society", this exploratory work is founded on a recognition of the need to move beyond a two-way consideration of telecommunications and transport. The three-way interaction between physical travel, virtual mobility and social participation will be increasingly significant. Such interactions are continually evolving and yet are under-researched and poorly understood.

Past expectations of the positive impacts that ICT might have on travel and transport have often led to disappointment. This suggests that we should be cautious when looking to what virtual mobility via the Internet might deliver to an integrated transport policy. This is not to say that there will not be positive impacts to be realised and adverse impacts to guard against but it points to a need to consider future scenarios that account for more than merely the immediate (technically and financially achievable) possibilities that the Internet can deliver. Key societal and institutional aspects must also be considered. Table 3 is based on a thorough appraisal by Geels and Smit (2000) (using insights from the field of technological studies) of past images of the impact of ICT on traffic and travel. It highlights pitfalls and lessons that should serve to guide subsequent research and speculation concerning the Internet's evolving role, nature and effects on transport. 


\section{Table 3}

\section{Concluding discussion}

At the beginning of the new millennium the future is perhaps as uncertain as it ever was. For the transport profession there is a growing realisation and recognition of how much the future of transport is inextricably linked to the future developments of society and lifestyles and technologies. The multidisciplinary and multifaceted nature of issues incumbent on the transport profession to address are at risk of being overwhelming. It is tempting to assume that the nature and extent to which the Internet will impact upon transport is beyond our control or even our responsibility. Yet we must not ignore the complexities but confront them. There has been considerable work over recent years done by Mokhtarian, Salomon and others in terms of understanding telecommunications-transport interactions. Golob and Regan (2001) have also recently contributed a wide ranging paper on the topic. Across this literature the issues and potential consequences for transport of technology are well documented. However, compelling empirical evidence remains a scarcity, particularly with specific regard to the Internet. The rapidly maturing nature of the Internet and the proportions of populations that have access to it also mean that 'past performance is not a guarantee of future performance' in terms of the knowledge base we have.

We are seeing a cultural change taking place alongside the technology revolution. People are becoming more exposed and familiar with the information age and are adjusting their habitual behaviours accordingly. Back in 1986 Salomon discussed the potential impacts of teleshopping. Yet at that time the web had not even been invented, nor had most people predicted the pace at which it would enter into common use or anticipated the versatility and flexibility of the medium. Perhaps the degree of access to and quality of virtual services will at some point reach a threshold where impacts on personal travel become more marked. We should remember too that the web and other developments concerning the Internet are still in 
their infancy. What we know of the Internet today, impressive though it can seem, is likely to be paled into insignificance by what it will become. The transformation over 90 years from Henry Ford's Model T of 1908 to the Ford Mondeo of 1998 in terms of comfort, quality, and performance is perhaps an apt analogy of how we should expect the 'Model T Internet' of today to develop in the future, and in far less time than 90 years.

Transport policymakers are as yet not taking sufficient account (with the exception of traveller information services' developments such as Transport Direct) of the Internet it would seem in terms of its (indirect) impacts on personal travel. Lyons et al (2001) in their discussion of this issue note that whilst in the UK government's integrated transport policy (DETR, 1998) it states that "we are committed to making fullest possible use of new technologies to deliver the New Deal for transport”, in the government's subsequent $£ 180$ billion ten-year spending plan for transport (DETR, 2000a) the document notes only that "the likely effects of increasing Internet use on transport and work patterns are still uncertain, but potentially profound, and will need to be monitored closely" and that "predictions of the effects of greater use of the Internet, of e-commerce, and of teleworking vary considerably”. At present physical mobility and accessibility fall firmly within the remit of transport policy. The same is not true of the virtual counterparts in spite of them being able to achieve broadly similar goals and impacting upon physical mobility and accessibility.

It is suggested therefore that in the longer run, virtual mobility and access afforded by the Internet and other forms of electronic communication should be explicitly addressed as part of an integrated transport policy. There remains a need to be able to forecast the uptake of new technology and assess its transport impacts before drawing firm policy conclusions. Nevertheless the nature of this paper warrants some final remarks suggesting what the transport policy response concerning the Internet should be. 
From several commentaries cited earlier, the temptation might be to concede that history tells us that increasing use of the Internet is not likely to lead to a reduction in travel and can therefore do little to support transport policy in its aims of reducing the length and number of motorised trips. Indeed society appears to embody an inherent need or desire for 'quotas' of mobility. Yet we cannot ignore that in terms of specific activities, such as shopping and working, for some (and a growing number of) people on some occasions the Internet is enabling virtual access to substitute for physical access and in many cases removing trips by car from our roads. It would appear that the problem arises in the consequent generation of new trips enabled by virtual mobility's saving in travel time. Crucial to whether or not the Internet can make a positive contribution to transport policy objectives is whether the newly generated trips are undertaken by car.

The popularity and opportunities of the Internet have principally arisen through market forces. In policy terms the appeal of Internet use as an alternative to physical travel is firstly that it is a 'carrot' rather than a 'stick' - it currently widens rather than restricts choice and benefits rather than penalises the individual in terms of travel time and cost savings. Secondly, the delivery of access to virtual mobility is not costing billions of pounds from the transport purse unlike other policy measures to encourage use of alternatives to the car.

It is the author's belief therefore that the transport policy response to the Internet should be two-fold:

1. Seek to accentuate positive effects of substitution that may be principally driven by market forces; and

2. Seek to refine and extend existing policies to ensure that newly generated travel demand is met through greater use of cycling, walking and public transport use and that other 'secondary' effects are suppressed. 
For example in areas where the frequency of Internet grocery shopping is high or growing, private non-residential parking charges for out-of-town supermarkets could be introduced to discourage car journeys when the alternative of virtual access is available. Such charges could then be used to subsidise store access via public transport for sectors of the public who either do not have home Internet access or access to a car. Alternatively charges might also subsidise renewal and expansion in the number of (smaller) city/town centre grocery retailing outlets.

Parking charges in city centres might be increased with major leisure attractions encouraged or required to build the price of public transport access to the attraction into the overall ticket price. Such measures would encourage the public to invest their saved travel time and cost (accrued from substitution) more sustainably. The potential secondary effect of residential relocation further from the workplace arising from increasing amounts of teleworking could be suppressed by fiscal incentives for either employers or employees to live within a specified distance from the workplace (i.e. a catchment area policy).

The Internet does not present a utopia for transport policy but rather some complex issues to grapple with. Yet we cannot afford not to consider its role in an integrated transport policy when, thus far, it seems that public transport (particularly for local travel) is unlikely by itself to be able to arrest society's dependence upon and use of the car in a world where lifestyles increasingly demand a flexibility and convenience of participation in time and space.

\section{References}

Adams, J. (2000). The Social Implications of Hypermobility Proc. Workshop The Economic and Social Implications of Sustainable Transportation , Ottawa, 95-134. Available at: http://www1.oecd.org/env/docs/epocppct993.pdf [accessed 19/04/02]. 
Austin, J. (1999). Towards comprehensive national public transport information on the Internet: the PTI Web site. Proc. AET European Transport Conference, Public Transport, Planning and Management, University of Cambridge, England, September, PTRC, 151-163.

Cairns, S. (1996). Delivery alternatives: Successes and failures of home delivery services for food shopping. Transport Policy, 3(4), 155-176.

CNN (2001). Microsoft, Tesco put groceries on Pocket PC. 18 July. Available at: http://www.cnn.com/2001/TECH/ptech/07/18/msoft.tesko.groceries.idg/index.html [accessed 19/11/01].

Cornwell, B. and Lundgren, D.C. (2001). Love on the Internet: involvement and misrepresentation in romantic relationships in cyberspace vs. realspace. Computers in Human Behaviour, 17, 197-211.

DETR (1998). A New Deal for Transport Better for Everyone. Transport White Paper, Department of the Environment, Transport and the Regions, July, TSO, London. Available at: http://www.detr.gov.uk/itwp/ paper/ [accessed 19/11/01].

DETR (2000a). Transport 2010 - The Ten Year Plan, Department of the Environment, Transport and the Regions, July, TSO. Available at: http://www.detr.gov.uk/trans2010/plan/ [accessed 19/11/01].

DETR (2000b). Transport Statistics Great Britain: 2000 Edition. Department of the Environment, Transport and the Regions, October, TSO. Available at: http://www.transtat.dtlr.gov.uk/tables/tsgb00/text/tsgb.htm [accessed 19/11/01].

Dodgson, J. (2000). Motors and modems revisited: The role of new technology in reducing travel demands and traffic congestion. NERA, London, May.

DOE/DOT (1994). Planning Policy Guidance Note 13: Transport. Department of the Environment and Department of Transport, HMSO, March. 
eMORI (2001). Technology Tracker. October. Available at:

http://www.mori.com/emori/tracker.html [accessed 19/11/01].

Fingerle, G., Lock, T. and Slevin, R. (1998). JourneyWeb: a Protocol for a Distributed Public Transport Planner. Proc. European Transport Conference, Public Transport Planning and Operations, Loughborough, September, 145-154.

Geels, F.W. and Smit, W.A. (2000). Failed technology futures: pitfalls and lessons from a historical survey. Futures, 32(2000), 867-885.

Golob, T.F. and Regan, A.C. (2001). Impacts of information technology on personal travel and commercial vehicle operations: research challenges and opportunities. Transportation Research, 9C, 87-121.

Handy, S. and Mokhtarian, P.L. (1996). Forecasting telecommuting An exploration of methodologies and research needs. Transportation, 23, 163-190.

Hepworth, M. and Ducatel, K. (1992). Transport in the Information Age - Wheels and Wires. Chapter 3: The Telecommunications-Transport Trade-off, Belhaven Press, 2949.

Hjorthol, R.J. (2002). The relation between daily travel and use of the home computer. Transportation Research Part A, 36 (2002), 437-452.

Illegems, V., Verbeke, A. and S’Jegers, R. (2001). The potential of teleworking as an urban traffic demand management tool: the case of Brussels, the Belgian capital. Proc. $9^{\text {th }}$ World Conference on Transport Research, Seoul, July.

Internet Software Consortium (2001). Internet Domain Survey. Available at: http://www.isc.org/ [accessed 19/11/01].

Kenyon, S., Lyons, G. and Rafferty, J. (2002). Transport, Social Exclusion and the Internet Could Virtual Mobility Help to Alleviate Social Exclusion? Proc. $34^{\text {th }}$ Universities Transport Studies Group Annual Conference, Edinburgh. 
Lund, J. and Mokhtarian, P. (1994). Telecommuting and residential location: theory and implications for commute travel in the monocentric metropolis. Transportation Research Record 1463, 10-14.

Lyons, G.D. (1998). An Assessment of Teleworking as a Practice for Travel Demand Management. Transport, 129(4), 195-200, ICE.

Lyons, G., Harman, R., Austin, J. and Duff, A. (2001). Traveller Information Systems Research: A Review and Recommendations for Transport Direct. Department for Transport, Local Government and the Regions, August. Available at: http://www.dtlr.gov.uk/itwp/transdirect/travinf/pdf/travinf.pdf [accessed 19/11/01].

Lyons, G., Marsden, G., Beecroft, M. and Chatterjee, K. (2001). Transportation Requirements. Transport Visions Network, Landor Publishing. Available at: http://www.trg.soton.ac.uk/research/TVNetwork/reports/report2.htm [accessed 19/11/01].

Mokhtarian, P.L. (1990). A Typology of Relationships Between Telecommunications and Transportation. Transportation Research, 24A(3), 231-242.

Mokhtarian, P.L. (1991). Telecommuting and travel: state of practice, state of the art. Transportation, 18(4), 319-342.

Mokhtarian, P.L. (1996). The Information Highway: Just because we're on it doesn't mean we know where we're going. World Transport Policy and Practice, 2(1/2), 24-28. Available at: http://www.engr.ucdavis.edu/ its/telecom/nrp12.html [accessed 19/11/01].

Mokhtarian, P.L. (1997). Now that Travel Can Be Virtual, Will Congestion Virtually Disappear? Scientific American, October. Available at: http://www.sciam.com/1097issue/1097mokhtarian.html [accessed 19/11/01]. 
Niles, J.S. (1994). Beyond telecommuting: a new paradigm for the effect of telecommunications on travel. Global Telematics.

Nilles, J.M. (1991). Telecommuting and urban sprawl: mitigator or inciter?. Transportation, $18,411-432$.

NUA (2001). How Many Online? Available at http://www.nua.ie/surveys/how_many_online/ [accessed 19/11/01].

Office for National Statistics (2001a). Internet Access. quarterly release, September. Available at http://www.statistics.gov.uk/pdfdir/int0901.pdf [accessed 19/11/01]. Office for National Statistics (2001b). Internet Access. quarterly release, June. Available at http://www.statistics.gov.uk/pdfdir/int0601.pdf [accessed 19/11/01].

Office for National Statistics (2001c). Internet Access. quarterly release, March. Available at http://www.statistics.gov.uk/pdfdir/int0301.pdf [accessed 19/11/01].

Office for National Statistics (2001d). Labour Market Spotlight. Labour Market Trends, 109(10), October, 469. Available at http://www.statistics.gov.uk/downloads/theme_labour/LMT_October01.pdf [accessed 19/11/01]

Ortúzar, J. de D. and Willumsen, L.G. (1998). Modelling Transport. p. 153, Wiley. Retail Logistics Task Force (2001). @ Your Home - New Markets for Customer Service and Delivery, Foresight, DTI.

Robins, N. and Roberts, S. (1996). Rethinking Paper Consumption. International Institute for Environment and Development, London, September. Available at: http://www.poptel.org.uk/iied/smg/pubs/rethink3.html [accessed 19/11/01].

Rowlatt, A. (2001). Measuring E-commerce: Developments in the United Kingdom. Economic Trends, 575, Office for National Statistics, October. Available at 
http://www.statistics.gov.uk/themes/economy/articles/general/extracts/downloads/E_ Commerce.pdf [accessed 19/11/01].

Salomon, I. (1986). Telecommunications and Travel Relationships: A Review.

Transportation Research, 20A(3), 223-238.

Salomon, I. (1998). Technological change and social forecasting: the case of telecommuting as a travel substitute. Transportation Research, 6C, 17-45.

Schafer, A. (1998). The Global Demand for Motorized Mobility. Transportation Research, 32A(6), 455-477.

Slevin, R. (1997). Presenting Local Travel Information on the World Wide Web:

Buckinghamshire and Beyond. Proc. European Transport Forum, Public Transport Planning and Operations, Brunel University, September, 195-206.

The Institute of Logistics and Transport (1999). Netting More Passengers: The Fundamentals of Travel Information on the Web. May, London. Available at http://www.iolt.org.uk/accreditation/netting.doc [accessed 19/11/01].

Thrift, N. (1999). Information and Communication Technology and the Social Sciences. Position Paper for UK-Nordic Meeting, April.

UK online (2000). Annual Report, September. Available at http://www.iagchampions.gov.uk/ukonline/progress/anrep1/010.htm [accessed 19/11/01].

Urry, J. (1999). Automobility, Car Culture and Weightless Travel: A Discussion paper. Project SceneSusTech, Department of Sociology, Lancaster University. Available at http://www.comp.lancs.ac.uk/sociology/soc008ju.html [accessed 17/04/02].

US Census Bureau (2001). Home Computers and Internet Use in the United States: August 2000. September. Available at: http://www.census.gov/prod/2001pubs/p23-207.pdf [accessed 19/11/01]. 


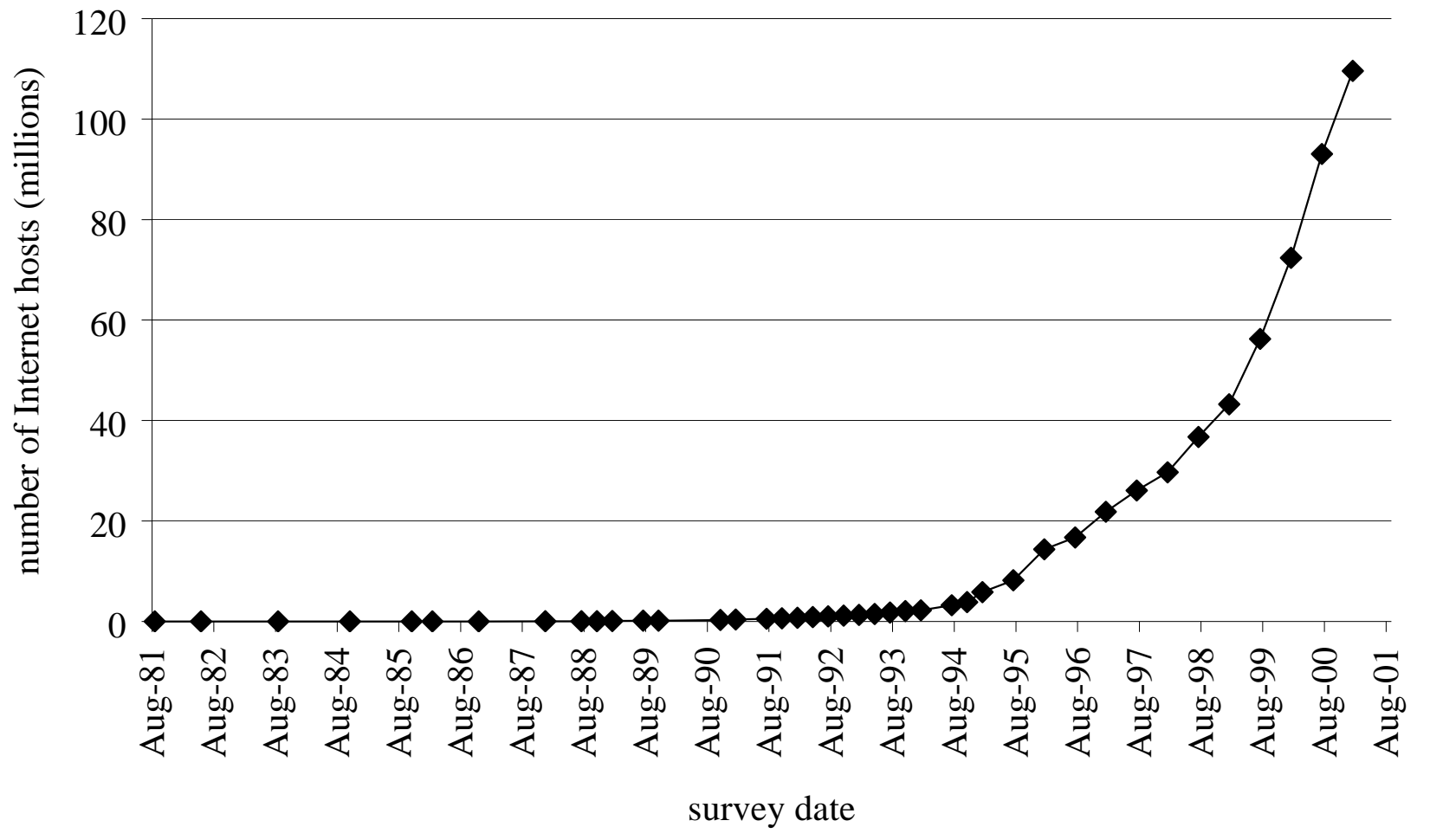

Fig. 1. Internet size measured over time (Internet Software Consortium, 2001) 


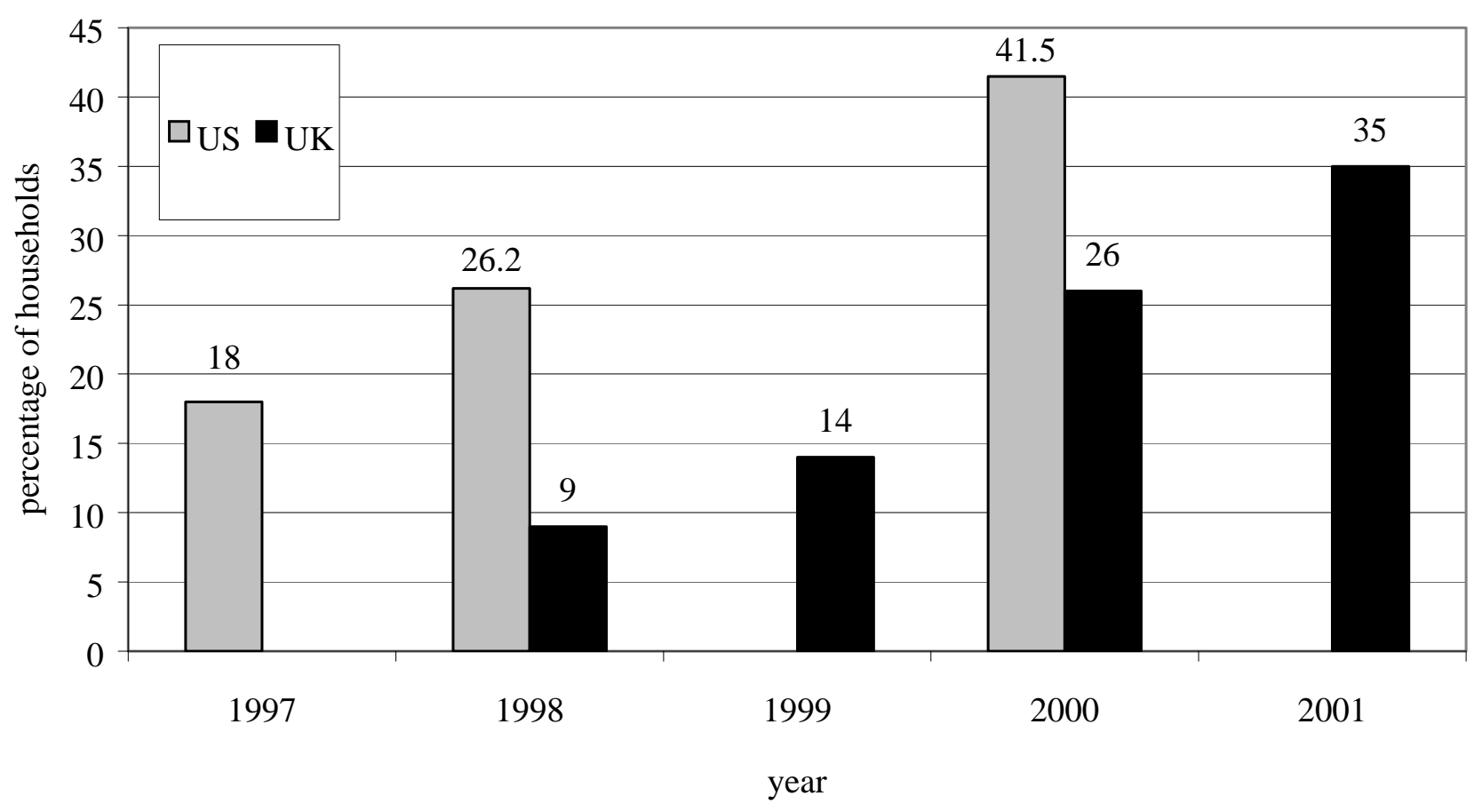

Fig. 2. Percentage of households with access to the Internet (US Census Bureau, 2001) (Office for National Statistics, 2001a) 


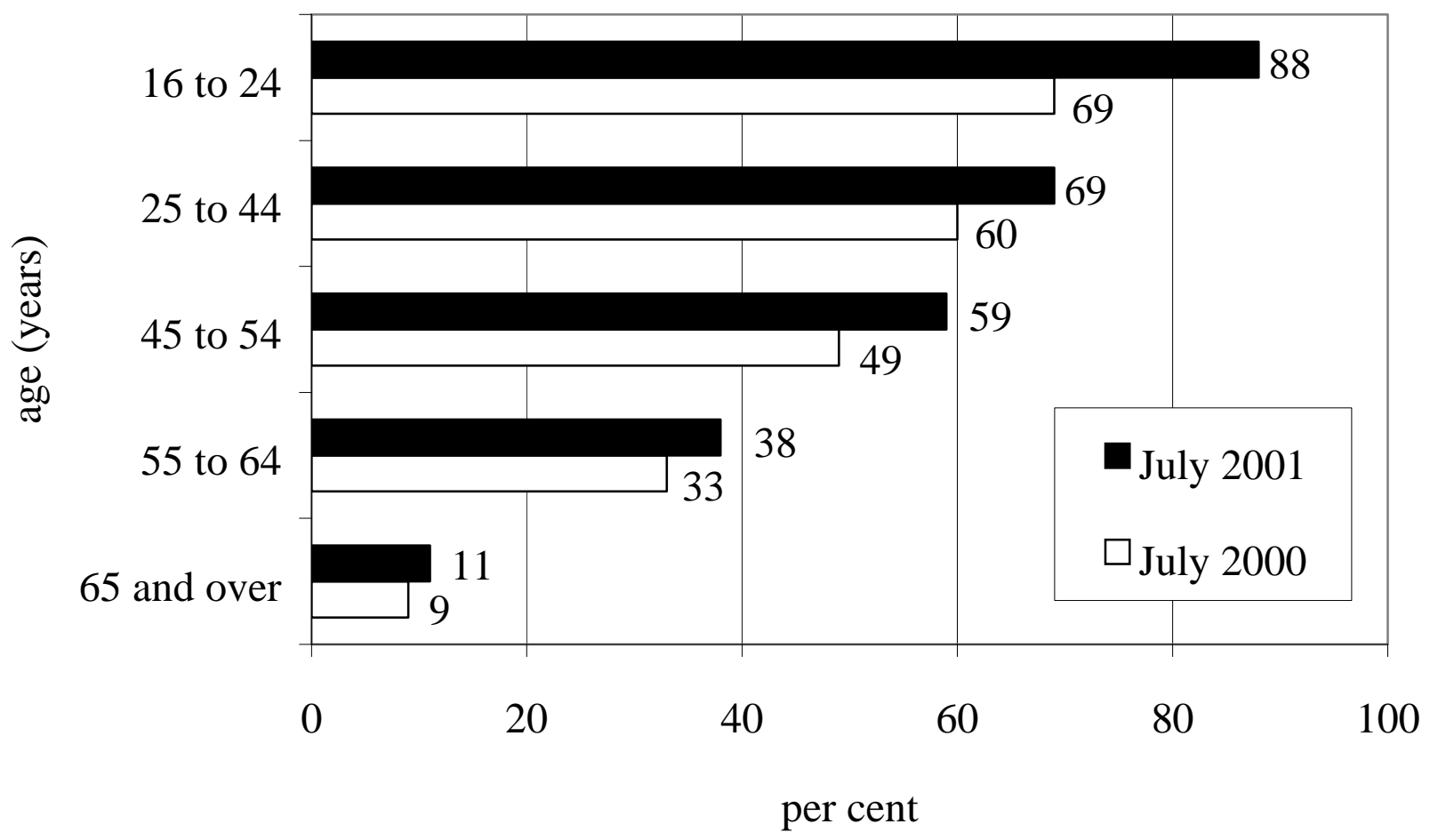

Fig. 3. UK adults who have used the Internet (Office for National Statistics, 2001a) 


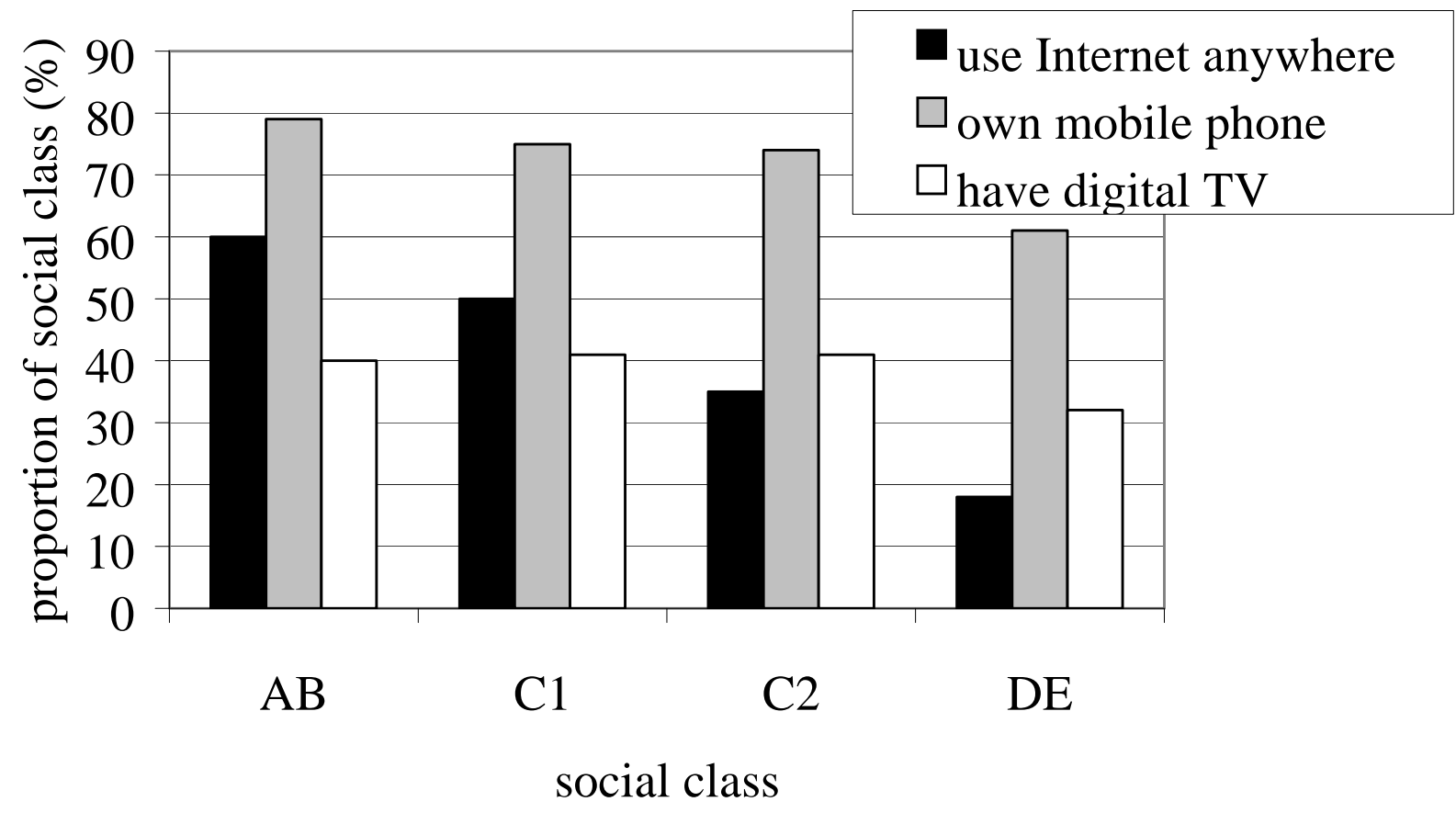

Fig. 4. Per cent of each social class who use key technologies (e-MORI, 2001) 
Table 1

Journeys per person per year by main mode and purpose in Great Britain: 1997/99 (DETR, 2000b)

\begin{tabular}{|c|c|c|c|}
\hline Journey purpose & $\begin{array}{r}\text { All } \\
\text { modes }\end{array}$ & $(\%)$ & $\begin{array}{r}\text { Car/van } \\
\text { driver/passenger } \\
\end{array}$ \\
\hline commuting & 164 & (16) & 114 \\
\hline business & 37 & (4) & 29 \\
\hline education & 67 & (6) & 22 \\
\hline escort education & 50 & (5) & 26 \\
\hline shopping & 221 & (21) & 129 \\
\hline other escort & 81 & (8) & 70 \\
\hline other personal business & 105 & (10) & 66 \\
\hline visiting friends at home & 140 & (13) & 97 \\
\hline visiting friends elsewhere & 45 & (4) & 25 \\
\hline social/entertainment & 61 & (6) & 45 \\
\hline holidays/day trips & 30 & (3) & 22 \\
\hline other, including just walk & 45 & (4) & 2 \\
\hline all purposes & 1046 & (100) & 647 \\
\hline
\end{tabular}


Table 2

Number of teleworkers ('000s) in the UK (Office for National Statistics, 2001d) (http://dialspace .dial.pipex.com/town/parade/hg54/twstats97.htm)

\begin{tabular}{ccccc}
\hline & Teleworker $^{1}$ & Home-based $^{2}$ & Occasional $^{3}$ & All \\
\hline 1999 & 255 & 693 & 357 & 1305 \\
2001 & 332 & 832 & 513 & 1677 \\
$\%$ increase & 30 & 20 & 44 & 29 \\
\hline
\end{tabular}

${ }^{1}$ Teleworker homeworkers work mainly in their own home in their main job

${ }^{2}$ Home-based teleworkers work in various locations in their main job using home as a base

${ }^{3}$ Occasional teleworkers do not usually work at home or use home as a base but spend at least one day a week teleworking in these locations 
Table 3

Key features that have shaped images of the future role of new technologies (adapted from Geels and Smit)

\begin{tabular}{|c|c|}
\hline Contemporary concerns and hopes & $\begin{array}{l}\text { Perceptions of the future are shaped and coloured by current } \\
\text { problems and aspirations resulting in optimistic rather than } \\
\text { plausible scenarios }\end{array}$ \\
\hline New technological trajectories & $\begin{array}{l}\text { The pathway of technological innovation and product development } \\
\text { may significantly change introducing new possibilities and } \\
\text { expectations concerning the role in, and impacts on society of the } \\
\text { technology }\end{array}$ \\
\hline New for old substitution & $\begin{array}{l}\text { The role of a new technology is often phrased in terms of replacing } \\
\text { or substituting the old technology whilst in reality old and new } \\
\text { technologies often co-exist, serving different markets, } \\
\text { circumstances or purposes. }\end{array}$ \\
\hline Social practices neutral & $\begin{array}{l}\text { It is often wrongly assumed that the pool of social practices and } \\
\text { needs remains unchanged thereby implying that new technology } \\
\text { will (only) substitute certain social practices. In reality the pool of } \\
\text { social practices can increase. }\end{array}$ \\
\hline Narrow functional thinking & $\begin{array}{l}\text { Through only functional thinking, new technologies can be judged } \\
\text { capable of enabling the purpose of an activity to be fulfilled. This } \\
\text { neglects to consider other social and psychological aspects of an } \\
\text { activity that may not be addressed. }\end{array}$ \\
\hline Societal embedding & $\begin{array}{l}\text { The process of societal embedding of new technologies can be } \\
\text { viewed an unproblematic when in practice many social and } \\
\text { institutional adjustment processes have to take place which may not } \\
\text { be straightforward and can take some time to achieve. }\end{array}$ \\
\hline Hopeful monstrosities & $\begin{array}{l}\text { Promoters in particular of an emerging technology can voice } \\
\text { unrealistically high expectations. This may be to serve the purpose } \\
\text { of creating a 'breathing space' for investment and development to } \\
\text { continue. It may also be a consequence of neglecting the co- } \\
\text { evolution of technology and society, and underestimating the } \\
\text { practical difficulties and resulting slowness of processes of societal } \\
\text { embedding of technology. }\end{array}$ \\
\hline
\end{tabular}

